\title{
Molecular detection of Pasteurella multocida Type B causing haemorrhagic septicemia in cattle and buffaloes of Bangladesh
}

\section{MS Ara, MT Rahman, M Akhtar, M Rahman, KHMNH Nazir, S Ahmed, ML Hossen, MFR Khan, MB Rahman*}

Department of Microbiology and Hygiene, Faculty of Veterinary Science, Bangladesh Agricultural University,

Mymensingh-2202, Bangladesh

\begin{abstract}
Hemorrhagic septicemia (HS) is an acute septicemic disease that primarily affects cattle and buffaloes. The disease is caused by Pasteurella multocida sero types B:2 and E:2. The objective of this study was to isolate $P$. multocida from clinical cases and to confirm its identity using polymerase chain reaction (PCR) based approach. Clinical samples of two suspected cases of haemorrhagic septicemia of cattle and buffalo from Mymensingh and Rajshahi districts respectively were collected. Two isolates were isolated from these suspected cases and primarily identified as P. multocida based on morphological study, staining properties, and cultural and biochemical characteristics. The isolates were confirmed initially as $P$. multocida at genus level by PCR using genus specific primers. Later, the isolates were confirmed as P. multocida type B, the causal agent of haemorrhagic septicemia, by PCR with primers specific for P. multocida type B. These isolated organisms can be used as vaccine candidate for the production of effective vaccine against haemorrhagic septicemia.
\end{abstract}

Key words: Haemorrhagic Septicemia, cattle, buffaloes, Pasteurella multocida type B, PCR

Progressive Agriculturists. All rights reserve

*Corresponding Author: bahanurr@gmail.com

\section{Introduction}

Haemorrhagic septicaemia (HS) is an acute and highly fatal septicemic disease of cattle and buffaloes caused by Pasteurella multocida. The disease has a high morbidity and mortality in cattle, particularly in buffaloes. $P$. multocida are classified into several serotypes based on their capsular and somatic antigens. According to the capsular polysaccharides P. multocida according are classified into five serotypes designated A, B, D, E and F, while according to the cell wall lipopolysaccharides typing they are classified into 16 somatic serotypes (Cartet, GR., 1955; Carter and Alwis, 1989). The general and biochemical properties of the various strains are very similar, and from this point of view these organisms all belong to the single species, but different serotypes show different pathogenicity when tested in various hosts. The etiology of HS is P. multocida serotype B: 2 and E: 2 (Annas et al., 2014; Chung et al., 2015; Marza et al., 2015).

P. multocida, based on pathogenicity could be either those causing a HS or those causing nonhaemorrhagic septicaemia. In addition, pasteurellosis causes great economic losses in sheep, goats, pigs, dogs, poultry, quails, ducks and sometimes in wild animals such as tiger, lion, leopard, panther, etc (De Alwis, 1996). In cattle, the is characterized by a rapid course, fever, oedematous swelling in the headthroat-brisket region, swollen and haemorrhagic lymph nodes and presence of numerous subserous petechial haemorrhages (Carter and De Alwis, 1989). P. multocida is a small, non-motile, Gram negative coccobacillary rod, inhabiting the nasopharynx and gastro-intestinal tract of many wild and domestic 
animals and produces disease when the animals are under stress (De Alwis, 1996). High ambient temperature, overcrowding, inadequate ventilation, transportation and malnutrition are factors, linked with the onset of the disease (Stahel et al., 2009).

Although there are reports on the occurrence of HS in Bangladesh (Hafiz, 2012; Akhtar, 2013), however, as far as we know, none of the studies have identified the etiological agent of HS using molecular based approach. The aim of the present study was to isolate and identify accurately $P$. multocida from suspected cases of HS by molecular technique i.e., PCR, so that the isolates could later be used for the development of effective vaccine to control the diseases in Bangladesh.

\section{Materials and Methods}

\section{Isolation and identification of Pasteurella}

For the isolation of $P$. multocida edematous fluid was collected from the throat of buffaloes of Rajshahi $(\mathrm{N}=1)$ and cattle of Mymensingh $(\mathrm{N}=1)$ regions that showed characteristics signs of HS. The sampleswere immediately transported to the Bacteriology laboratory of the Department of Microbiology and Hygiene, Bangladesh Agricultural University, Mymensingh. Isolation and identification of $P$. multocida was carried out based on morphology, staining, cultural and biochemical characteristic, as described by Cheesbrough (2006).

\section{Polymerase Chain Reaction (PCR) for Pasteurella multocida type B}

Conformation of the isolated organisms as $P$. multocida type $\mathrm{B}$, the causal agent of haemorrhagic septicemia in buffaloes and cattle were done based on PCR as described by Townsend et al. (1998), Panna et al. (2015) and Akhtar et al. (2016). Initially PCR was carried out to confirm the isolate as Pasteurella spp. using the primer KMT1T7 5'-ATCCGC-TAT-TTA-CCC-AGT-GG-3' and KMT1SP6 5'-GCT-GTA-AAC-GAA-CTC-GCC-AC-3'. This was then followed by conformation of the isolates as $P$. multocida type B using the specific primers pairs KTT72 5'-AGG-CTC-GTT-TGG-ATT-ATG-AAG$3^{\prime}$ and KTSP61 5'-ATC-CGC-TAA-CAC-ACTCTC-3'. Briefly, for PCR bacterial DNA was first extracted using Wizard genomic DNA Purification
Kit (Promega, USA) according to the instruction of the manufacturers to use as PCR template. Extraction of DNA and its quality was checked by running $5 \mu \mathrm{L}$ suspension of the extracted DNA in a $1 \%(\mathrm{w} / \mathrm{v})$ agarose gel. All the PCR was done in a final $25 \mu \mathrm{L}$ volume containing $12.5 \mu \mathrm{L} \quad \mathrm{PCR}$ mastermix (Promega, USA), $1 \mu \mathrm{L}$ of each primer $(10 \mathrm{pmol})$, PCR grade water $8.5 \mu \mathrm{L}$ and DNA template $2 \mu \mathrm{L}$. The thermal profile used for the Pasteurella genus specific PCR was performed as follows with slight modification from Townsend et al. (1998): initial denaturation at $94^{\circ} \mathrm{C}$ for $5 \mathrm{~min}$, followed by 30 cycles of denaturant at $94^{\circ} \mathrm{C}$ for $1 \mathrm{~min}$, annealing at $49^{\circ} \mathrm{C}$ for $1 \mathrm{~min}$, and elongation at $72^{\circ} \mathrm{C}$ for $1 \mathrm{~min}$ and finally a final extension at $72^{\circ} \mathrm{C}$ for $9 \mathrm{~min}$. The thermal profile used for the $P$. multocida type B specific PCR was also done as per protocol described by Townsend et al. (1998) with slight modification: initial denaturation at $95^{\circ} \mathrm{C}$ for $5 \mathrm{~min}$, followed by 30 cycles of denaturant at $95^{\circ} \mathrm{C}$ for $1 \mathrm{~min}$, annealing at $49^{\circ} \mathrm{C}$ for $1 \mathrm{~min}$, and elongation at $72^{\circ} \mathrm{C}$ for $7 \mathrm{~min}$ and finally a final extension at $72^{\circ} \mathrm{C}$ for $9 \mathrm{~min}$. Following the completion of PCR, $5 \mu \mathrm{L}$ PCR products were loaded into $2 \%$ agarose gel (w/v) along with $1 \mu \mathrm{L} 6 \mathrm{X}$ loading dye for electrophoresis in $1 \mathrm{X}$ TBE buffer at $100 \mathrm{~V}$ for $35 \mathrm{~min}$. A standard $100 \mathrm{bp}$ DNA ladder (Promega, USA) was also loaded in the same gel to check the size of the amplified PCR products. Prior to casting the gel, ethidium bromide $(0.5 \mu \mathrm{g} / \mathrm{mL})$ was added to the gel. The PCR products were visualized under UV light in an image documentation system (Bio Rad, USA).

\section{Results and Discussion}

Haemorrhagic septicemia caused by $P$. multocida is a devastating disease of domestic and wild animals. The disease is often associated with severe economic loss in the livestock industries. HS, together with anthrax and black quarter, are responsible for an estimated economic loss of US\$148.6 million each year (Ahmed, 1996; Mondal and Yamage, 2014). In this study, P. multocida was isolated and identified from suspected cases of HS of cattle and buffalo by conventional bacteriological method. On blood agar media, the isolated bacteria produced small, round, whitish colonies with no hemolysis. Gram's staining revealed presence of Gram negative small rod shaped 
bacteria (Figure 1). The isolated organisms fermented dextrose, sucrose and mannitol but not maltose and lactose. These fermented sugars produced acid without gas. The organisms also gave positive indole test and negative methyl red (MR), voges-proskauer (VP) test. All these findings are similar to those reported by Cheesbrough (2006) as specific for Pasteurella spp.

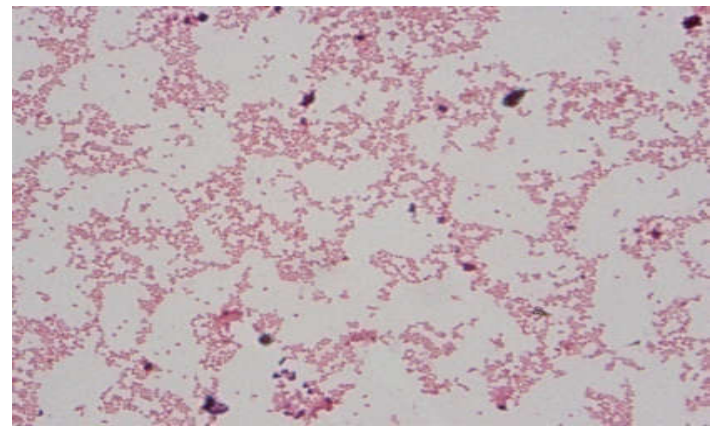

Figure 1. Gram's staining showing small Gram negative rod bacteria $(100 \mathrm{X})$

In the past, several studies have been carried out in Bangladesh on the isolation and identification of $P$. multocida by conventional microbiological methods from filed cases, vaccine development and its efficacy determination (Choudhury et al., 1985; Hafez, 2012). However, as far as we know, none of these studies were carried out at molecular level. To the best of our knowledge, this is probably the first study in Bangladesh describing the PCR based detection of $P$. multocida from suspected clinical cases of HS in Bangladesh.

The isolated organisms were found Gram negative and morphologically they were coccobacillary in shape. On Blood agar the isolated organisms produced whitish, opaque, circular, translucent colonies and with no hemolysis that resembles the characteristics colonies of P. multocida, as described by Choudhury et al. (1985), Cheesbrough (2006) and Rahman et al. (2016). Biochemically the isolated organisms were found positive for oxidate, catalase, indole tests, negative from MR and VP test. The organisms were found positive for sucrose, dextrose, mannitol and negative for lactose and maltose. Results of these biochemical tests suggested that the isolated organisms could be considered as $P$. multocida. Shivachandra et al. (2011) also reported similar biochemical characteristics for $P$. multocida type B.
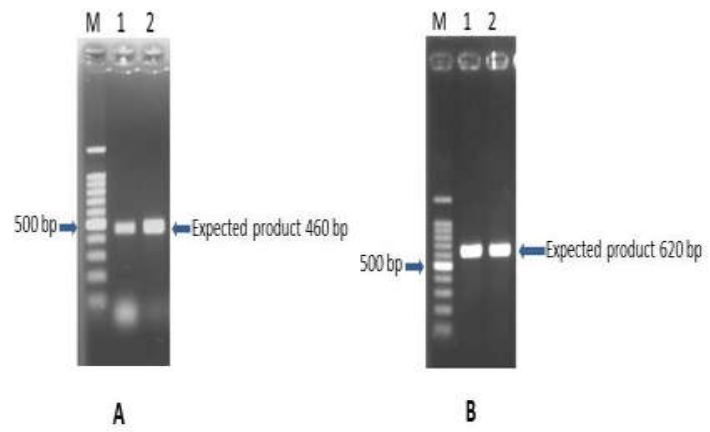

Figure 2. PCR amplification of Pasteurella multocida.A. Amplification using the primers KMT1SP6 and KMT1T7 specific for the genus Pasteurella. B. Amplification using the primers KTSP61 and KTT72specific for the Pasteurella multocida. Lane 1= Isolate from cattle, Lane $2=$ Isolate from buffalo, $M=100$ bp DNA marker

PCR is a rapid, robust and highly specific molecular technique for confirmatory detection of many species of bacteria including P. multocida (OIE Manual, 2008). The development of molecular tools has paved the way for rapid and specific identification of infectious agents, thus PCR was used for identification of $P$. multocida. During the present study, both the buffalo and cattle isolates of $P$. multocida exhibited species specific amplification of approximately 460-bp size using primers KMT1SP6 and KMT1T7 (Townsend et al., 1998). These findings confirmed the results obtained by Townsend et al. (2000), Javia (2004) and Patel (2004), who reported the specificity of this primer pair for all $P$. multocida isolates. Townsend et al. (1998) reported that the primer pairs gave amplification from all strains of $P$. multocida (all serotypes and capsular serogroups), the three subspecies i.e., P. multocida subsp. multocida, P. multocida subspp. gallicida, $P$. multocida subspp. septica and also $P$. canis biotype 2. Dutta et al. (2001) also carried out PM-PCR using various serotypes of $P$. multocida. 
Presumptive identification of HS caused by type-Bspecific $P$. multocida is also possible by PCR amplification (Townsend et al., 1998). To date, $P$. multocida type-B-specific PCR performed by Townsend et al. (1998) remains 100\% specific for the detection of this organism. In the present study $P$. multocida type B cultures both from buffalo and cattle with the predominant somatic antigen being either type 2 or 5 are identified by the amplification of a 620-bp fragment with the KTSP61 and KTT72 primers. Results of the PCR are presented in Figure 2. A standard PCR protocol which is slightly modified from Townsend et al. (1998) successfully was optimized to detect $P$. multocida type B circulating in Bangladesh.

\section{Conclusion}

P. multocida has been isolated from the filed cases of haemorrhagic septicemia of cattle and buffalo in Bangladesh. Besides, molecular identification of the isolated organism as $P$. multocida type $\mathrm{B}$ is confirmed by PCR. The isolate can be used in effective vaccine development.

\section{Conflict of interest}

The authors declare that they have no competing interest.

\section{Acknowledgement}

The research work was financially supported by the World Bank under HEQEP (CP-007).

\section{References}

Ahmed S (1996). Status of some bacterial diseases of animals in Bangladesh. Asian Livest. 21: 112114.

Akhtar M (2013). Isolation, identification and characterization of Pasteurella multocida from chicken and development of oil based vaccine. MS thesis of department of Microbiology and Hygiene, Bangladesh Agricultural University, Mymensingh, Bangladesh.

Akhtar M, Rahman MT, Ara MS, Rahman M, Nazir KHMNH, Ahmed S, Hossen ML, Rahman MB (2016). Isolation of Pasteurella multocida from chickens, preparation of formalin killed fowl cholera vaccine, and determination of efficacy in experimental chickens. J. Adv. Vet. Anim. Res. 3: $45-50$.

Annas S, Zamri-Saad M1, Jesse FF, Zunita Z (2014). New sites of localisation of Pasteurella multocida B:2 in buffalo surviving experimental haemorrhagic septicaemia. BMC Vet. Res. 10:88.

Carter GR (1955). Studies on Pasteurella multocida. I. A haemagglutination test for identification of serological types. Am. J. Vet. Res. 16: 481-484.

Carter GR, De Alwis (1989). Haemorrhagic septicemia, In: Adlam C and Rutter JM (eds) Pasteurella and Pasteurellosis. Academic Press, London, UK. pp. 131-160.

Cheesbrough M (2006). District Laboratory Practice in Tropical Countries.Part 2.2nd edition, Cambridge University Press, New York. USA. pp. 45-62.

Choudhury KA, Amin MM, Rahman A, Ali MR (1985). Investigation of natural outbreak of fowl cholera. Bangladesh Vet. J. 19: 49-56.

Chung EL, Abdullah FF, Ibrahim HH, Marza AD, Zamri-Saad M, Haron AW, Lila MA, Norsidin MJ (2015). Clinico-pathology, hematology and biochemistry responses in buffaloes towards Pasteurella multocida type B: 2 immunogenlypopolysaccharide via oral and intravenous routes of infection. Microb. Pathog. 91:141-154.

De Alwis (1996). Haemorrhagic septicaemia: Clinical and epidemiological features of the disease. International workshop on diagnosis and control of H.S. Bali. Indonesia, May, 28-30.

Dutta TK, Singh VP, Kumar AA (2001). Rapid and specific diagnosis of animal pasteurellosis by using PCR assay. Indian J. Comp. Microbiol., Immunol. Infect. Dis. 22:43-46.

Hafiz RM (2012). Isolation and identification of Pasteurella multocida from cattle and development of oil based inactivated vaccine, MS in Microbiology, Dept. of Microbiology \& Hygiene, Faculty of veterinary science, Bangladesh agricultural university, Mymensingh, Bangladesh.

Javia BB (2004). Isolation and identification of Pasteurella multocida of animal and avian origin 
by cultural, biochemical and molecular techniques.M.V.Sc. thesis submitted to Gujarat Agricultural University, Anand Campus; pp. 42120.

Marza AD, Abdullah FFJ, Ahmed IM, Chung ELT, Ibrahim HH, Zamri-Saad M, Omar AR, Bakar MZA, Saharee AA, Haron AW, Lila MAM (2015). Involvement of nervous system in cattle and buffaloes due to Pasteurella multocida B:2 infection: A review of clinicopathological and pathophysiological changes. J. Adv. Vet. Anim. Res. 2: 252-262.

Mondal SP, Yamage M (2014). A retrospective study on the epidemiology of anthrax, foot and mouth disease, haemorrhagic septicaemia, peste des petits ruminants and rabies in Bangladesh, 20102012. PLoS One. 9(8): e104435.

OIE (2008). OIE Terrestrial manual, pp.744.

Panna SN, Nazir KHMNH, Rahman MB, Ahamed S, Saroare MG, Chakma S, Kamal T, Majumder UH (2015). Isolation and molecular detection of Pasteurella multocida Type A from naturally infected chickens, and their histopathological evaluation in artificially infected chickens in Bangladesh. J. Adv. Vet. Anim. Res. 2: 338-345.

Patel HK (2004). Biochemical characterization, antimicrobial sensitivity, PCR based detection and mouse pathogenicity of Pasteurella multocida field isolates. MVSc thesis submitted to the Anand Agricultural University. pp. 10-38.

Rahman MH, Shahiduzzaman ANM, Haque ME, Nazir KHMNH, Rahman (2016). Development of Experimental Oil based Inactivated HS Vaccine from field Isolates of Pasteurella multocida from Cattle in Bangladesh. Int. J. Vaccines Vaccin. 2(2): 00027. DOI: 10.15406/ijvv.2016.02.00027

Shivachandra SB, Viswas KN, Kumar AA (2011). A review of hemorrhagic septicemia in cattle and buffalo. Anim. Health Res. Rev. 12: 67-82.

Stahel ABJ, Hoop RK, Kuhnert P, Korczak BM (2009). Phenotypic and genetic characterization of Pasteurella multocida and related isolates from rabbits in Switzerland. J. Vet. Diag. Invest. 21:793-802.

Townsend KM, Boyce JD, Chung JY, Frost AJ, Adler B (2000). Genetic organisation of Pasteurella multocida cap loci and development of a multiplex capsular PCR typing system. J. Clin. Microbiol. 39: 924-929.

Townsend KM, Front AJ, Lee CW, Papadimitrious JM, Dawkins HJS (1998). Development of PCR assays for species and type specific identification of Pasteurella multocida isolates. J. Clin. Microbiol. 36: 1096-1100. 